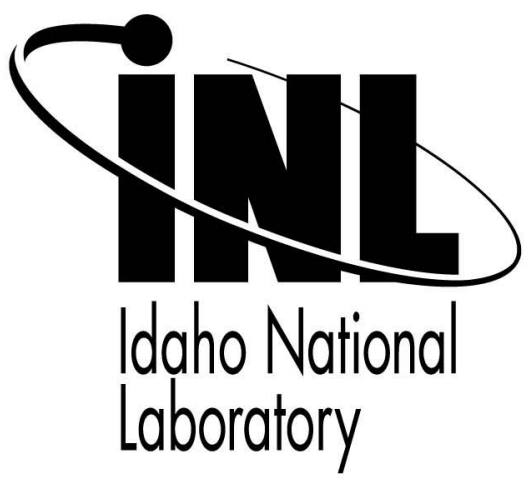

\section{7th ANS Topical Meeting on the Technology of Fusion Energy}

\author{
L. C. Cadwallader \\ T. Pinna \\ P. I. Petersen
}

November 2006

This is a preprint of a paper intended for publication in a journal or proceedings. Since changes may be made before publication, this preprint should not be cited or reproduced without permission of the author. This document was prepared as an account of work sponsored by an agency of the United States Government. Neither the United States Government nor any agency thereof, or any of their employees, makes any warranty, expressed or implied, or assumes any legal liability or responsibility for any third party's use, or the results of such use, of any information, apparatus, product or process disclosed in this report, or represents that its use by such third party would not infringe privately owned rights. The views expressed in this paper are not necessarily those of the United States Government or the sponsoring agency. 


\title{
POWER SUPPLY RELIABILITY ESTIMATES FOR EXPERIMENTAL FUSION FACILITIES
}

\author{
L. C. Cadwallader, ${ }^{1}$ T. Pinna, ${ }^{2}$ and P. I. Petersen ${ }^{3}$ \\ ${ }^{1}$ Idaho National Laboratory, PO Box 1625, Idaho Falls, ID 83415-3860,Lee.Cadwallader@inl.gov \\ ${ }^{2}$ ENEA, via Enrico Fermi, 45000444 Frascati (Rome), Italy \\ ${ }^{3}$ General Atomics, PO Box 85608, San Diego, CA 92186-5608
}

This paper presents the results of a task to analyze the operating experience data for large, pulsed power supplies used at the DIII-D tokamak. This activity supports the International Thermonuclear Experimental Reactor (ITER) project by giving fusion-specific reliability values for large power supplies that energize neutral beams and magnets. These failure rate data are necessary to perform system availability calculations and to make estimates of the frequency of safety-significant events (e.g., power supply arcs or fires) that might occur in other fusion facilities such as ITER. The analysis shows that the DIII-D data results compare well with the results of similar data analysis work that the Italian National Agency for New Technologies, Energy and the Environment (ENEA) has performed on the JET tokamak and compare fairly with data from two accelerators.

\section{INTRODUCTION}

The International Energy Agency (IEA), based in Brussels, sponsors collaboration on the environmental, safety, and economic aspects of magnetic fusion. One of the tasks (Task 5) within that collaboration is development of a fusion component failure rate database. The Task 5 component failure rate data are to be used to quantify probabilistic safety assessment, support traditional safety analysis, quantify reliability, availability, maintainability, and inspectability (RAMI) analyses, and support any other uses where field experience can provide feedback to fusion facilities. Task 5 began in 1989 and has had two parts. The first part of the task was to "harvest" already-published data from high-technology industries that can be readily applied to fusion components. ${ }^{1}$ The second part of Task 5 is to collect and analyze operating experience data from existing tokamaks and other fusion experiments. The data harvesting task initially populated a computerized database developed at ENEA-Frascati. ${ }^{2,3}$ The ongoing operating experience data analysis is providing further information to the database. ${ }^{4-9}$ This information is used in safety assessment for upcoming fusion experiments.
Data collection and analysis from one tokamak requires verification to prove that the data are representative of other machine operating experiences. By agreement among Task 5 participants, component failure rate data values require some level of validation for entry into the database. Generally, validation is done by comparing two independent data values; good data compare within a factor of 3 , fair data within a factor of 10 , and poor data compare at larger than a factor of 10 (Ref. 1). Good, and to a lesser extent fair, comparisons demonstrate that the component failure rates are representative of tokamaks in general and are not the result of some unique, site-specific issue.

Developing a second, independent data set for validation comparison is difficult. Task participants have endeavored to develop data sets that are complimentary for the purpose of validation, and have developed a plan where data from similar systems of similar tokamaks are analyzed. The power supply data presented here are the result of a task to generate an independent data set from DIII-D operating experiences and compare it to similar work that has been completed on operating experiences from the JET Joint Undertaking. 5

Power supplies were chosen for analysis because these are important support system components in any tokamak. While ITER is a first-of-a-kind experiment, predecessor tokamaks and the equipment used at those tokamaks provide a good indication of the reliability and operational availability of future experiments. Some of the power supplies presently in use, for example the neutral beam (NB) power supplies, are directly similar to those to be used on next-generation machines such as ITER, so the operating experience of these units is directly important to ITER safety and availability.

This analysis includes all power supplies. Some of the DIII-D and JET power supplies are quite large, such as those that supply power to the resistive magnetic field coils, and will not be used in ITER. However, the 
amounts of electrical energy that these pulsed power supplies deliver make them relevant to other ITER uses and to uses at other tokamaks. Therefore, including all power supplies in the data analysis broadened the data set and provided completeness to the analysis.

\section{DIII-D OPERATING EXPERIENCE DATA}

The DIII-D experiment, located in California, operates in pulsed mode, with usually 5 seconds of pulse operating time followed by a shutdown lasting 10-15 minutes while pulse data are saved, components are cooled, and the machine is prepared for another plasma pulse. ${ }^{10}$ Therefore, power supplies are "on duty" for entire operating days with down times for cooldown after each pulse. The main DIII-D power supply parameters are given in Table I (Refs. 10 and 11). The installation dates show that most power supplies were installed for use on the Doublet III machine. Given that the early lifetime of such power supplies is on the order of 4 years, ${ }^{5}$ the DIII-D units are considered to be mature components that were commissioned for use on the DIII-D beginning in 1987.

Over 1,700 trouble reports on power supplies were downloaded from the DIII-D Trouble Report Database ${ }^{12}$ for analysis. These reports were categorized by their power supply identifier and by the faulted subcomponent in the database. The reports were then tabulated by the subcomponent's failure mode to allow component failure rate calculations. The data results are given in Tables II and III (Ref. 13).

The US data analysis used several failure modes, which had to be summed and equated to the JET failure modes to allow comparison. Failure to operate (the power supply does not operate when needed), failure to continue to run (the power supply fired but did not complete the shot), and degraded operation (the power supply did not deliver rated outputs or operated spuriously) were summed and equated to the JET data category of 'fail to operate/spurious operation'. The DIII-D failure modes of fail to preset, alarm condition, and erratic alarm were summed and equated to the JET category of 'alarm/erratic alarm/fail to preset'. The DIII-D failure rates for all failure modes were summed and equated to the JET category of 'generic trouble'. Power supply failure rates given are per hour of operating day. The DIII-D operating hours used in the analysis were those reported in annual operations reports. In some years at DIII-D the neutral beam injectors were used continuously, and other years they were used only $70 \%$ of the time, for an average usage of $90 \%$. This value was applied to the overall machine operating time.

TABLE I. DIII-D Power Supply Information

\begin{tabular}{|c|c|c|c|c|}
\hline \multirow[b]{2}{*}{ Power Supply Identifier } & \multirow[b]{2}{*}{ Load Supplied $^{\mathrm{a}}$} & \multicolumn{2}{|c|}{ Power Supply Parameters } & \multirow[b]{2}{*}{ Year Installed } \\
\hline & & $\begin{array}{c}\text { Voltage } \\
(\mathrm{kV})\end{array}$ & $\begin{array}{c}\text { Amperage } \\
(\mathrm{kA})\end{array}$ & \\
\hline $\mathrm{B}$ & TF magnet coils & 1 & 130 & 1976 \\
\hline $\mathrm{E}$ & Ohmic heating magnet coils & 0.6 & 300 & 1976 \\
\hline X Copper -20 units & PF magnet coils & 0.48 & 3 & 1979 \\
\hline HX Chopper-16 units & PF magnet coils & 0.96 & 3 & 1979 \\
\hline HV1 & HX choppers for PF magnets & 1.2 & 20 & 1981 \\
\hline HV2 & HX choppers for PF magnets & 1.2 & 20 & 1984 \\
\hline D1 & $\mathrm{X}$ choppers for PF magnets & 0.6 & 10 & 1977 \\
\hline D2 & $\mathrm{X}$ choppers for PF magnets & 0.6 & 14 & 1984 \\
\hline $\mathrm{T} 1, \mathrm{~T} 2$ & $\mathrm{X}$ choppers for PF magnets & 0.6 & 6 & 1982 \\
\hline V1 & $\mathrm{X}$ choppers for PF magnets & 0.52 & 14 & 1977 \\
\hline NB & NB magnet power & 0.08 & 0.6 & 1978 \\
\hline NB Filament Power Supply & NB ion source filament & 5.5 & 0.02 & 1978 \\
\hline NB Arc Power Supply & NB arc & 0.07 & 3 & 1978 \\
\hline UCV7 & NB HV power to accelerator & 80 & 0.1 & 1982 \\
\hline UCV5 & NB HV power to accelerator & 80 & 0.1 & 1982 \\
\hline
\end{tabular}

a. $\mathrm{TF}=$ toroidal field, $\mathrm{PF}=$ poloidal field, $\mathrm{NB}=$ neutral beam, $\mathrm{HV}=$ high voltage.

Note: All of these power supplies were installed before the inception of the DIII-D Trouble Report Database in May 1987. All units are considered to be mature components. Some units have been swapped to other locations, overhauled, or repaired in the course of DIII-D operations. 
TABLE II. Overall Failure Rates for DIII-D Coil Power Supplies, 1987-2004

\begin{tabular}{|c|c|c|c|c|}
\hline Power Supply System & $\begin{array}{c}\text { Number of } \\
\text { Faults in } \\
\text { Trouble Reports }\end{array}$ & $\begin{array}{l}\text { System Run Time } \\
(\mathrm{hr})\end{array}$ & $\begin{array}{l}\text { Failure Rate } \\
\qquad(/ \mathrm{hr})\end{array}$ & $\begin{array}{l} \pm \text { Standard } \\
\text { Error }\end{array}$ \\
\hline $\begin{array}{l}\text { B Power Supply, TF Coil Power Supply System- } \\
\text { All Modes or Generic Trouble }\end{array}$ & 289 & 13,150 & $2.2 \mathrm{E}-01$ & $4.1 \mathrm{E}-03$ \\
\hline $\begin{array}{l}\text { B Power Supply, TF Coil Power Supply System- } \\
\text { Alarm/Erratic Alarm/Fail to Preset }\end{array}$ & 31 & 13,150 & $2.4 \mathrm{E}-03$ & $4.3 \mathrm{E}-04$ \\
\hline $\begin{array}{l}\text { B Power Supply, TF Coil Power Supply System- } \\
\text { Fail to Operate and Spurious Operation }\end{array}$ & 258 & 13,150 & $2.0 \mathrm{E}-02$ & $1.2 \mathrm{E}-03$ \\
\hline $\begin{array}{l}\text { E Power Supply, Ohmic Coil Power Supply } \\
\text { System_-All Modes or Generic Trouble }\end{array}$ & 212 & 13,150 & $1.6 \mathrm{E}-02$ & $1.1 \mathrm{E}-03$ \\
\hline $\begin{array}{l}\text { E Power Supply, Ohmic Coil Power Supply } \\
\text { System-Alarm/Erratic Alarm/Fail to Preset }\end{array}$ & 32 & 13,150 & $2.4 \mathrm{E}-03$ & $4.3 \mathrm{E}-04$ \\
\hline $\begin{array}{l}\text { E Power Supply, Ohmic Coil Power Supply } \\
\text { System-Fail to Operate and Spurious Operation }\end{array}$ & 180 & 13,150 & $1.4 \mathrm{E}-02$ & $1.0 \mathrm{E}-03$ \\
\hline $\begin{array}{l}\text { PF Power Supply Set, Coil Power Supply System- } \\
\text { All Modes or Generic Trouble }\end{array}$ & 921 & 13,150 & $7.0 \mathrm{E}-02$ & $2.3 \mathrm{E}-03$ \\
\hline $\begin{array}{l}\text { PF Power Supply Set, Coil Power Supply System- } \\
\text { Alarm/Erratic Alarm/Fail to Preset }\end{array}$ & 118 & 13,150 & $9.0 \mathrm{E}-03$ & $8.3 \mathrm{E}-04$ \\
\hline $\begin{array}{l}\text { PF Power Supply Set, Coil Power Supply System- } \\
\text { Fail to Operate and Spurious Operation }\end{array}$ & 803 & 13,150 & $6.1 \mathrm{E}-02$ & $2.2 \mathrm{E}-03$ \\
\hline $\begin{array}{l}\text { DIII-D All Coil Power Supply Systems-All Modes } \\
\text { or Generic Trouble }\end{array}$ & 1,422 & 13,150 & $1.1 \mathrm{E}-01$ & $2.9 \mathrm{E}-03$ \\
\hline $\begin{array}{l}\text { DIII-D All Coil Power Supply Systems- } \\
\text { Alarm/Erratic Alarm/Fail to Preset }\end{array}$ & 181 & 13,150 & $1.4 \mathrm{E}-02$ & $1.0 \mathrm{E}-03$ \\
\hline $\begin{array}{l}\text { DIII-D All Coil Power Supply Systems-Fail to } \\
\text { Operate and Spurious Operation }\end{array}$ & 1,241 & 13,150 & $9.4 \mathrm{E}-02$ & $2.7 \mathrm{E}-03$ \\
\hline
\end{tabular}

TABLE III. Overall Failure Rates for DIII-D NB Power Supplies, 1987-2004

\begin{tabular}{|c|c|c|c|c|}
\hline Power Supply System & $\begin{array}{c}\text { Number of } \\
\text { Faults in } \\
\text { Trouble Reports }\end{array}$ & $\begin{array}{l}\text { System Run Time } \\
\text { (hr) }\end{array}$ & $\begin{array}{l}\text { Failure Rate } \\
\qquad(/ \mathrm{hr})\end{array}$ & $\begin{array}{l} \pm \text { Standard } \\
\text { Error }\end{array}$ \\
\hline $\begin{array}{l}\text { DIII-D All NB Power Supply Systems-All Modes } \\
\text { or Generic Trouble }\end{array}$ & 32 & 11,835 & $2.7 \mathrm{E}-03$ & $4.8 \mathrm{E}-04$ \\
\hline $\begin{array}{l}\text { DIII-D All NB Power Supply Systems- } \\
\text { Alarm/Erratic Alarm/Fail to Preset }\end{array}$ & 2 & 11,835 & $1.7 \mathrm{E}-04$ & $1.2 \mathrm{E}-04$ \\
\hline $\begin{array}{l}\text { DIII-D All NB Power Supply Systems-Fail to } \\
\text { Operate and Spurious Operation }\end{array}$ & 30 & 11,835 & $2.5 \mathrm{E}-03$ & $4.6 \mathrm{E}-04$ \\
\hline
\end{tabular}

From Tables II and III, one can see that the coil power supplies had many trouble reports filed on fault events, and consequently the failure rates were high. The NB power supplies are, in general, more modest units with lower amperage. These units had very few trouble reports and very low failure rates, which is reasonable since the units are well designed and not pushed as hard in DIII-D operations compared to their design parameters.

The overall collection of power supply trouble report data also held a few important citations of serious failures. Over the collection time period, there were 20 events of 
smoke, 1 cited fire event, 15 electrical arc events, 5 electrical equipment explosions, 4 events of sparks issued from power supplies, and 18 events of components such as circuit boards and diodes being electrically overstressed and "blowing up." (The electronic parts blowing up are not as severe or energetic as the explosions.) Thus, 21 smoke/fire events in 13,150 total operating hours (at $\approx 750$ operating hours/year) gives 1 smoke/fire event per year. The electrical arc events give 0.86 events per operating year, another plant operational event. The five electrical explosions and four spark events give frequencies of $0.3 /$ year and $0.2 /$ year, respectively. Using the ITER frequency definitions, these frequencies would be in the plant operational events frequency category. The DIII-D safety provision of making exclusion areas around the electrical equipment while it is energized is a prudent safety precaution and a best practice for ITER design.

\section{JET JOINT UNDERTAKING OPERATING EXPERIENCE DATA ANALYSIS}

The component failure rate data approach taken with JET in the UK was more robust than the U.S. approach. The researchers reviewed plant-specific historical records, including operation records (e.g., electronic records and hand-written logbooks), failure investigation reports, maintenance and repair records, and the annual operations and technical reports on JET operations. They also conducted plant personnel interviews. ${ }^{5,6}$ These more detailed data have supported the analysis very well.

Like the DIII-D experiment, JET operates in a pulsed mode. Pulses can be produced at a typical rate of about 22 pulses in 16 hours, and each pulse can last for up to 60 seconds in duration. During a JET pulse, the main power demands are the toroidal field coils, the poloidal transformer coils, the plasma equilibrium coils, and the divertor coils. They require a total amount of energy of nearly $10,000 \mathrm{MJ}$, and a peak power of over 1,000 MW for the pulse time. Like most tokamaks, a motor-generator flywheel system is used to supplement the power taken from the electrical utility power grid.

There are some differences between JET and DIII-D. JET is a larger machine and operates at different voltages. The national power grid for JET operates at $400 \mathrm{kV}$ and is stepped down to $36 \mathrm{kV}$ for distribution in the JET facility. The JET toroidal field coils have a maximum of $67 \mathrm{kA}$ and $5.8 \mathrm{kV}$. A JET operating day was taken to be 16 hours rather than the 8.5 hours at DIII-D. The JET system-level failure rate data per operating hour are given in Table IV (Refs. 5 and 6).

\section{DATA COMPARISON}

The data in Tables II, III, and IV show several differences. First, the DIII-D data set spans from 1987 to 2004 versus the JET data time frame of 1997-2003. Even with the longer time frame, the DIII-D machine ran for less overall hours than JET. This discrepancy of operating times is not believed to be caused by reliability issues, but rather a factor of available funds for operations - namely the high cost of electric power (which can be over $4 \%$ of total tokamak operations costs) and the cost of consumable items such as cryogen and compressed gases.

The next difference is the number of reported faults in each of the categories for the overall coil systems. JET reported less overall faults than DIII-D. Initially this deviation was believed to be due to the fact that the DIII-D power supplies are older than the JET equipment-JET began operation in 1983 while many of

TABLE IV. Coil and NB power supply failure rates for troubles occurring during JET operating days, 1997-2003

\begin{tabular}{|l|c|c|c|c|}
\hline \multicolumn{1}{|c|}{ Power Supply System } & $\begin{array}{c}\text { Number of } \\
\text { Faults Recorded }\end{array}$ & $\begin{array}{c}\text { System Run Time } \\
\text { (hr) }\end{array}$ & $\begin{array}{c}\text { Failure Rate } \\
\text { (/hr) }\end{array}$ & $\begin{array}{c} \pm \text { Standard } \\
\text { Error }\end{array}$ \\
\hline Coil Power Supply Systems_-Generic Trouble & 990 & 14,864 & $6.7 \mathrm{E}-02$ & $2.1 \mathrm{E}-03$ \\
\hline $\begin{array}{l}\text { Coil Power Supply Systems_-Alarm/Erratic Alarm/ } \\
\text { Fail to Preset }\end{array}$ & 534 & 14,864 & $3.6 \mathrm{E}-02$ & $1.6 \mathrm{E}-03$ \\
\hline $\begin{array}{l}\text { Coil Power Supply Systems_Fail to Operate/ } \\
\text { Spurious Operation }\end{array}$ & 456 & 14,864 & $3.1 \mathrm{E}-02$ & $1.4 \mathrm{E}-03$ \\
\hline NB Power Supply Systems-Generic Trouble & 870 & 13,456 & $6.5 \mathrm{E}-02$ & $2.2 \mathrm{E}-03$ \\
\hline $\begin{array}{l}\text { NB Power Supply Systems_-Alarm/Erratic Alarm/ } \\
\text { Fail to Preset }\end{array}$ & 627 & 13,456 & $4.7 \mathrm{E}-02$ & $1.9 \mathrm{E}-03$ \\
\hline $\begin{array}{l}\text { NB Power Supply Systems-Fail to Operate/ } \\
\text { Spurious Operation }\end{array}$ & 243 & 13,456 & $1.8 \mathrm{E}-02$ & $1.2 \mathrm{E}-03$ \\
\hline
\end{tabular}


the DIII-D power supplies were installed in the 1970s, as shown in Table I. However, as part of the analysis, trouble reports per calendar year were plotted. ${ }^{13}$ Those plots showed no notable increases in trouble reporting in later years and no discernable trend of equipment end-oflife "wearout" failures at DIII-D. Therefore, component age should not be a factor in failure rate variances. Rather, different reporting criteria at the facilities may be the primary reason for this discrepancy.

The next variance between the tables is that JET reported more alarm/erratic alarm/fail to preset events than DIII-D. There could be several reasons for this deviation, but the primary reason is believed to be that the JET data carried more detail, with logbooks and personnel interviews, and such detail yielded more data regarding alarms. It is also possible that some of the DIII-D trouble report data may have been miscategorized during the data analysis. Counts might compare more favorably if more DIII-D data could be analyzed in a process of site visits similar to those that researchers conducted at JET. The JET data revealed that about $55 \%$ of all JET coil power supply faults were in the alarm category and $45 \%$ were in the failure to operate/spurious operation category. The DIII-D data were $13 \%$ and $87 \%$ in these respective categories. Comparing the two values of highest importance (i.e., the rates of power supplies failing to operate), gives $9.4 \mathrm{E}-02 / \mathrm{hr}$ for DIII-D and $3.1 \mathrm{E}-02 / \mathrm{hr}$ for JET. These two values show a factor of 3 difference, which is a good comparison of failure rates. For the alarm failure mode, DIII-D had a rate of $1.4 \mathrm{E}-02 / \mathrm{hr}$ and the JET rate was $3.6 \mathrm{E}-02 / \mathrm{hr}$, which are within a factor of three of each other, another good comparison.

Comparing the JET and DIII-D NB data, the NB power supply information from DIII-D was much sparser than the data from JET. The DIII-D NB power supply fail to operate rate was $2.5 \mathrm{E}-03 / \mathrm{hr}$ and the JET rate was $1.8 \mathrm{E}-02 / \mathrm{hr}$, which is over a factor of 7 difference. That is a fair comparison. The DIII-D data did not carry nearly the number of trouble reports expected for these power supplies. The small number of reports is believed to be due to these power supplies not having the high-energy output of the main magnet coil units. The DIII-D NB power supplies appear to be modest output units exhibiting high reliability. The NB power supplies deliver a few MW per pulse while the main power supplies for magnet coils deliver hundreds of MW per pulse. The main coil power supplies have perhaps a thousand silicon controlled rectifiers in their systems, whereas the NB power supplies have two vacuum tubes. Another issue is that the NB systems have had other, more troublesome components (e.g., ion sources) whose faults resulted in NB downtime which subsequently resulted in reductions to NB power supply duty factors. However, the discrepancy in the failure rates, particularly after receiving good comparisons of coil power supply failure rates, suggests that perhaps some DIII-D NB power supply troubles were dealt with immediately and did not reach the database for assignment to a system engineer. It is also possible that some NB trouble reports were categorized into other systems rather than power systems.

\section{OTHER POWER SUPPLY DATA}

Some reliability data were found in the literature about magnet power supplies at particle accelerators. The Advanced Photon Source uses $\approx 1,400$ power supplies that drive resistive magnets on its storage ring. These power supplies generate between 60 and $450 \mathrm{~A}$ direct current at 1,000 to $1,700 \mathrm{~V}$ to power the magnets, and operate on the order of 5,000 hr/year. If one power supply is lost, the beam storage is lost, so reliability is an important issue at the facility. Hillman ${ }^{14}$ gave information on the power supply mean time between failures (MTBF) that resulted in beam loss. Over four calendar years, the power supply MTBF was $118.95,89.96,86.36$, and 142.84 hours. Failure rates are the reciprocal of the MTBF, so the failure rates are $8.4 \mathrm{E}-03 / \mathrm{hr}, 1.1 \mathrm{E}-02 / \mathrm{hr}$, $1.2 \mathrm{E}-02 / \mathrm{hr}$, and $7 \mathrm{E}-03 / \mathrm{hr}$, or an average of $9.1 \mathrm{E}-03 / \mathrm{hr}$. Therefore, these independent data give power supply "failure to operate" failure rates on the order of $1 \mathrm{E}-02$ to 9E-03/hr. The JET data compare well to these particle accelerator data, and the DIII-D data compare fairly. This comparison is particularly important since fusion power supplies operate with more on/off pulses than accelerator power supplies.

The DA $\Phi$ NE accelerator power supplies are rated from 10 to $3,000 \mathrm{~A}$ and 6 to $1,250 \mathrm{~V} \mathrm{dc}$. This facility reported power supply failures over 5 years, with results on the order of 4.47 faults per two week $(336 \mathrm{~h})$ run times, or $1.3 \mathrm{E}-02 / \mathrm{hr}$ as an overall failure rate. ${ }^{15}$ This is a good to fair comparison for both DIII-D and JET data.

As the data show, these independent data sets also yield power supply failure rates that confirm the values calculated from DIII-D and JET data.

\section{CONCLUSIONS}

These data analyses show that the results coming from tokamak trouble report databases can be accurate in comparison to each other and to data sets generated at other high-technology facilities. The data results confirm each other and can be used to support ITER systems availability analysis and also studies of facility safety. The data on catastrophic failures of power supplies will 
be used in worker safety studies to provide safety zones and barriers to prevent additional equipment damage. These data results are useful to ITER and other tokamaks. The IEA task is ongoing; the next systems under analysis are plasma heating systems, another function that is essential to tokamak operations.

\section{ACKNOWLEDGMENTS}

The authors wish to thank the operations staff at both the DIII-D and JET tokamaks. Without their work to make records of equipment failures, this analysis would not have been possible. This work was prepared for the U. S. Department of Energy, Office of Fusion Energy Sciences, under DOE Idaho Field Office contract number DEAC07-05ID14517 and U.S. DOE contract DE-FC0204ER54698 with General Atomics.

\section{REFERENCES}

1. L. CADWALLADER and T. PINNA, "Progress Toward a Component Failure Rate Data Bank for Magnetic Fusion Safety," Proceedings of the International Topical Meeting on Probabilistic Safety Assessment (PSA '99), Washington, D.C., August 22-26, 1999, p. 11, American Nuclear Society (1999).

2. T. PINNA and L. CADWALLADER, "Component Failure Rate Data Base for Fusion Applications," Fus. Eng. Des., 51-52, 579 (2000).

3. T. PINNA, J. IZQUIERDO, M. T. PORFIRI, and J. DIES, "Fusion Component Failure Rate Database (FCFR-DB)," Fus. Eng. Des., 81, 1391 (2006).

4. T. PINNA, G. CAMBI, A. LO BUE, and C. RIZZELLO, Collection and Analysis of Data Related to Fusion Machines (JET and TLK) Operation Experience on Component Failures, FUS-TN-SASE-R-058, Associazione ENEA-EURATOM sulla Fusione, Frascati, Italy (2003).

5. T. PINNA, F. GRAVANTI, G. CAMBI, and P. POLINARI, JET Data Collection on Component Malfunctions and Failure of Neutral Injectors and Power Supply Systems, FUS-TN-SA-SE-R-121, Associazione ENEA-EURATOM sulla Fusione, Frascati, Italy (2004).

6. T. PINNA, G. CAMBI, and F. GRAVANTI, "Collection and Analysis of Component Failure Data from JET Systems," $8^{\text {th }}$ IAEA Technical Meeting on Fusion Power Plant Safety, Vienna, Austria, July 10 13, 2006, to be published in Nuclear Fusion.

7. L. C. CADWALLADER and P. I. PETERSEN, "Reliability Estimates for Oxygen Monitors," Proceedings of the $20^{\text {th }}$ Symposium on Fusion
Engineering, San Diego, California, October 14-17, 2003, p. 171, IEEE (2003).

8. L. C. CADWALLADER and P. I. PETERSEN, "Confinement Reliability Estimates for Vacuum System Components," Fusion Science and Technology, 44, 382 (2003).

9. L. C. CADWALLADER and P. I. PETERSEN, "Reliability Estimates for Power Supplies," Proceedings of the $21^{\text {st }}$ Symposium on Fusion Engineering, Knoxville, Tennessee, September 2629, 2005, IEEE (2005).

10. PROGRAM STAFF, System Design Description of DIII-D, GA-A-19264, General Atomics, San Diego, California (1989).

11. A. NEREM, DIII-D Power Supply, Design and Development, GA-A21957, General Atomics, San Diego, California (1995).

12. P. I. PETERSEN and S. M. MILLER, "The DIII-D Tokamak Trouble Report Database," Proceedings of the $14^{\text {th }}$ IEEE/NPSS Symposium on Fusion Engineering, San Diego, California, September 30October 3, 1991, p. 776, IEEE (1991).

13. C. J. O'CONNOR, L. C. CADWALLADER, and P. I. PETERSEN, Reliability of DIII-D Power Supplies, INL/EXT-06-11555, Idaho National Laboratory (in press).

14. A. HILLMAN, J. CARWARDINE, and G. SPRAU, "Magnet Power Supply Reliability at the Advanced Photon Source," Proceedings of the 2001 Particle Accelerator Conference, Chicago, Illinois, June 1822, 2001, p. 3657, IEEE (2001).

15. M. INCURVATI, R. RICCI, and C. SANELLI, "DAФNE Power Supply System: 5 Years of Experience and Statistics," Proceedings of the $8^{\text {th }}$ European Particle Accelerator Conference, Paris, France, June 3-7, 2002, p. 2478, European Physical Society Interdivisional Group on Accelerators and CERN (2002). Available at www.jacow.org. 